From the Association of Departments of Family Medicine

Ann Fam Med 2007;5:566-567. 10.1370/afm.783

\section{TALIKING THE LEGISLATIVE TALK: THE PATIENT-CENTERED MEDICAL HOME}

Recent commentaries in The Annals of Family Medicine summarize evidence that care delivered by an adequate workforce of family physicians in the context of a pervasive network of Patient-Centered Medical Homes is a powerful mechanism to improve healthcare outcomes and lower costs in the United States. These commentaries also describe characteristics of systems of healthcare and medical education which pose barriers to the development of such a workforce and the delivery of such care..$^{1-3}$

Over the past 15 months, members of Congress have abruptly given greater attention to this message. On September 28, 2006, the Patient-Centered Medical Home (PC-MH) was the focus of testimony to the Subcommittee on Health of the House Energy and Commerce Committee, which has principle jurisdiction over Medicare physician payment policy. Subcommittee chair, Rep Nathan Deal of Georgia, expressed support for legislation that creates incentives (such as per-member, per-month care coordination fees and lower out-of-pocket expenses for patients) that support practices that establish lasting relationships between patients and physicians in the context of a PC-MH. His committee's consensus support has touched off a series of pilot tests of the PC-MH, and Representative Deal himself has been characterized as a "champion, advocate, and defender" of the PC-MH as a centerpiece concept for healthcare reform.

Senator Dick Durbin of Illinois is sponsor and Sen Richard Burr of North Carolina is cosponsor of legislation, The Medical Homes Act of 2007, in which the $\mathrm{PC}-\mathrm{MH}$ is the focal point and which contains specific language to authorize Medical Home Demonstration Projects. The following comment by Senator Durbin is representative of a greater awareness among legislators of the importance of the PC-MH: "At a time when both healthcare costs and chronic illnesses are on the rise, we need a better way to provide care that is accessible, comprehensive, coordinated, and cost effective," said Durbin. "The Medical Homes Act of 2007 would make federal funding available for states to provide care to our nations most vulnerable-low income children and families. The Medical Home model can reduce costs and improve quality of healthcare services for every person in America."
It is now time for all family physicians to act on this groundswell of support in Congress for the PC$\mathrm{MH}$. On March 5, 2007, the American Academy of Family Physicians, the American Academy of Pediatrics, the American College of Physicians, and the American Osteopathic Association published a document entitled Joint Principles of the Patient-Centered Medical Home. This document articulates both evidence-based principles of the effective $\mathrm{PC}-\mathrm{MH}$ and a vision for care that will improve outcomes through quality improvement initiatives and health information technology. In dialogue with legislators, family physicians should use the term Patient-Centered Medical Home when describing their practice, and should clearly convey the elements contained in this document. The document and a commentary can be found in The American Family Pbysician. 4,5

Family physicians can best seize this great opportunity by regular communication with their senators, representatives, and state legislators. This is accomplished when family physicians develop lasting personal relationships with legislators and become the legislators' customary source of advice for healthcare issues. Family physicians must articulate compelling stories about care in the context of the PC-MH, and must also provide concise information in communication with legislators. One example of concise information which describes the PC-MH, provides a bibliography of its effectiveness, and can be used in discussions with legislators is a brochure entitled Primary Care: A Miracle of Modern Medicine. ${ }^{6}$ Useful information is also provided in a scientific review ${ }^{7}$ and by The Commonwealth Fund. ${ }^{8}$

The importance of a common language and unified voice cannot be overemphasized. As legislators are poised to implement healthcare reform, they should clearly understand the meaning of the words Family Physician, Family Medicine, and Patient-Centered Medical Home. These words should be heard over and over again as we advocate for legislation that supports a system of accessible, effective healthcare for all Americans, and rewards research and educational programs that promote such a system.

Jerry Kruse, MD, MSPH and the Association of Departments of Family Medicine

\section{References}

1. Kruse J. Family medicine legislative advocacy: our powerful message. Ann Fam Med. 2005;3(5):468.

2. Kruse J. Saving Medicare: "It's the workforce, stupid". Ann Fam Med. 2006;4(3):274.

3. Freeman J, Kruse J. Title VII: Our loss, their pain. Ann Fam Med. 2006;4(5):465

4. Kellerman R, Kirk L. Principles of the patient-centered medical home. Am Fam Physician. 2007;76(6):774. 
5. Kruse J. Improving care with the patient-centered medical home. Am Fam Physician. 2007;76(6):775.

6. UCSF Center for Excellence in Primary Care. http://www.ucsf.edu/ серс.

7. Starfield B, Shi L: The medical home, access to care, and insurance: a review of the literature. Pediatrics. 2004;113(5 Suppl):1493-1498.

8. Beal AC, Doty MM, Hernandez SE, Shea KK, Davis K. Closing the divide: how medical homes promote equity in health care: results from The Commonwealth Fund 2006 Health Care Quality Survey. The Commonwealth Fund. June 2007. http://www.commonwealthfund.org/publications/publications_show.htm?doc_id $=506814$.



From the Association of Family Medicine Residency Directors

Ann Fam Med 2007;5:567-568. 10.1370/afm.786.

\section{FAMILY MEDICINE: CARE FOR A LIFETIME}

In 1995 the faculty of Cabarrus Family Medicine Residency held our first retreat to formulate the mission, vision, and values of a new residency program that would train residents using 4 community private practices. We decided we needed a new model for a residency within a practice. In the spirit of not taking ourselves too seriously we came up with the Tricycle Model of Training (Figure 1).

In our program the big wheel driving and guiding our program is patient care. To this day you will hear us say, "The big wheel is patient care." Our practice exists to provide high-quality patient care with teaching and research linked to patient care by a strong frame of administration. The tricycle model is a dynamic one. The leadership of our program metaphorically "rides" this tricycle over the hills and valleys of American healthcare. The point of the model is that our teaching and research are driven by patient care. That being said, the model allows for flexibility in the relative sizes of the 3 wheels. Some programs have larger research and teaching wheels than others. Clearly, all 3 wheels are necessary and valuable to "ride" our discipline forward.

The last 10 years have been a sobering time in residency training with a $53 \%$ decrease in US seniors entering family medicine residencies. ${ }^{1}$ Residency programs spend countless hours recruiting qualified students. We have done our best to make our programs attractive to residents, but nevertheless, the numbers declined. If we reflect on the big wheel being patient care, then perhaps we should refocus our efforts, not so much on polishing our programs, but rather on making the practice of family medicine more enjoyable. The best thing we can do for recruitment to family medicine residency programs is to create a more satisfying life and career for those in practice. The good news is primary care is once again ascending in value to our health care system. The concept of the medical home makes such good sense that more and more people are beginning to support it.

Family medicine residency is the center point of a continuum of training that spans from medical school through early and later career learning after residency completion. All residency programs have office and hospital practices that must teach the skills our graduates will need to practice family medicine in the $21 \mathrm{st}$ century. The journey to the future begins with a vision of family medicine which I call "care for a lifetime." Here is my vision of what it could be, and what we need to train physicians to live the dream.

1. Every American has access to a medical home designed to provide primary care that keeps patients out of emergency rooms and hospitals, and improves chronic disease and preventive outcomes

2. The medical home is funded not only by E\&M codes, but also by management fees, and E-medicine fees.

3. We have translated the core values and services of family medicine so well that our patients and the public are able to articulate them.

4. We have defined a core set of knowledge, skills, and attitudes that must be mastered to graduate from a family medicine residency.

5. The funding of graduate medical education is transformed to equitably cover the true costs of training residents.

6. All residents train in certified medical homes and leave residency ready to be valuable contributors to their future practices.

7. The RRC requirements reflect the core skills of practice, are outcome based, and compliance with

\section{Figure 1.}

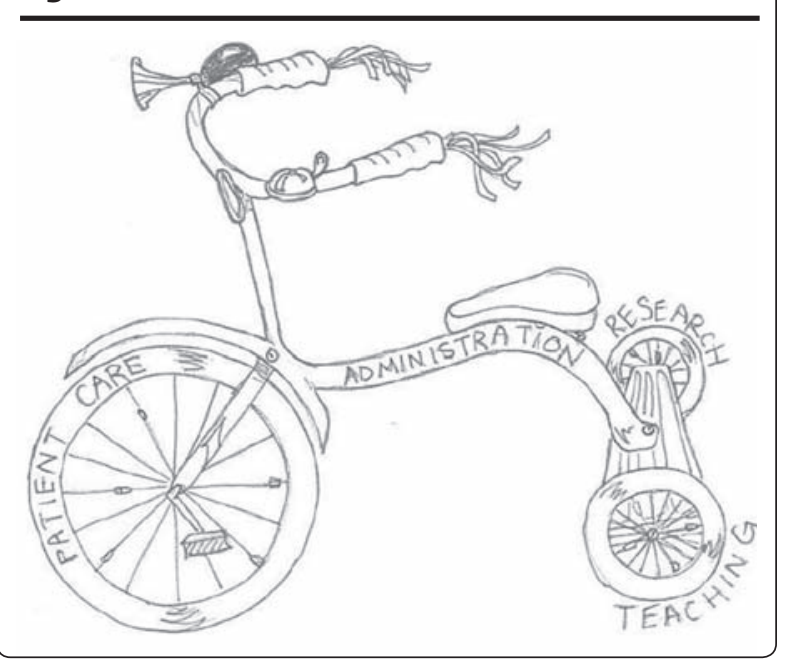

